\title{
Internet governance: towards a non-representational democracy
}

\section{Martin Hans Knahl*}

\author{
Network Research Group \\ University of Plymouth \\ Plymouth PL4 8AA, UK \\ E-mail: mknahl@plymouth.ac.uk \\ *Corresponding author
}

\section{Geoff Cox}

Art and Social Technologies Research Group

University of Plymouth

Plymouth PL4 8AA, UK

E-mail: gcox@plymouth.ac.uk

\begin{abstract}
Internet governance is a contentious topic referring to the global control and management of key internet resources such as IP addresses. Research suggests that the existence of an open market, transparency and competition are having a major impact on internet governance. Key players such as the ICANN are currently in the process of formulating the scope and agenda of future internet governance. Research suggests that institutional as well as market driven governance will remain present for network access and content. Additionally, network governance is increasingly configured in new ways that relate to the topography of distributed systems. The suggestion is that alternative forms are emerging from within a network culture that challenges established forms of governance and allow for the possibility of 'non-representational democracy'.
\end{abstract}

Keywords: internet governance; non-representational democracy; Internet Corporation for Assigned Names and Numbers; ICANN; World Summit on the Information Society; WSIS.

Reference to this paper should be made as follows: Knahl, M.H. and Cox, G. ( $\mathrm{xxx})$ 'Internet governance: towards a non-representational democracy', Int. J. Web Based Communities, Vol. X, No. Y, pp.000-000.

Biographical notes: Dr. Martin Knahl is currently a Lecturer at the University of Plymouth. He is a Research Fellow at the Centre for Information Security and Network Research. His research interests are in the areas of IT management and operation, internet governance and distributed service development and utilisation.

Dr. Geoff Cox is currently a Lecturer at the University of Plymouth (UK), where he manages the MA/MSc/MRes programmes in Digital Art and Technology. He is also a member of the research faculty of Transart Institute and the Adjunct Curator for Online Projects at Arnolfini, Bristol. He co-edited 
'Economising culture' and 'Engineering culture' as part of the DATA browser series (Autonomedia 2004 and 05), is a trustee of Kahve-Society and the Treasurer of the UK Museum of Ordure.

\section{Introduction to internet governance}

Internet governance is a hotly debated and relevant issue referring to the global control and management of key internet resources (Collins, 2006; Mueller, 1999). These resources include the internet root server system or domain name servers but also the allocation of IP addresses and domain names. Today the technical operation of the internet is relevant for the global economy and the internet provides a globally adopted communication medium, as well as provides a metaphor for an understanding of its operations. Thus political and technological aspects are thoroughly interwoven and cannot be separated (Castells, 1996; Kleinwaechter, 2004).

To describe a network simply as a set of interconnected nodes is deceptive. Nodes with a large number of links or connections account for uneven distribution within a given system. For instance, the World Wide Web is dominated by highly connected nodes or hubs and thus can be seen to not be the egalitarian space that many imagine it to be (Barabási, 2002). Hubs express power not centrally but in a distributed manner in keeping with contemporary descriptions of democracy. The distance between nodes depends on whether they are part of the same network or interconnected networks. Thus they may be dynamic, open-ended, multiple and without limits, yet at the same time demonstrate representational processes of inclusion and exclusion. The switches connecting networks together, or more accurately routers that connect different IP networks, is where power is demonstrated - where power is switched on or off. The networks that combine communications technologies and social structures are fundamental to the form of late capitalism that is commonly referred to as 'globalisation' (Castells, 1996). Over the last 50 years numerous cultural commentators have investigated the processes that facilitate globalisation (e.g., international collaboration in the areas of commerce or communication infrastructures) and the related political processes that express new forms of sovereignty (Keohane and Nye, 1998; Hardt and Negri, 2000). A number of key contributing factors such as economic and military power, agenda setting or global policy networks have been identified (Keohane and Nye, 1998; Slaughter, 2001). The dynamic development of the internet provides the infrastructure through which new services become possible and also acts as a metaphor through which they can become better understood. In particular, it is clear that control and governance are enacted in new ways that reflect the topography of distributed network systems. This can be characterised as 'governance without government' to describe the inherently paradoxical ways that power is now expressed (Hardt and Negri, 2000, pp.13-14).

This study identifies and outlines the most relevant internet deployment and governance implications and analyses the developments affecting internet governance. In terms of methodology the study follows a transdisciplinary approach that is in keeping with the socio-technical issues it describes. It considers different forms of governance given the dynamic structure of the internet as a network of networks. These can broadly be split into those that follow traditional organisational forms (that are broadly vertical in structure) and those that are collaborative and distributed in character (more horizontal in 
character). It can be argued that the main internet governance body lacks transparency and clear formalised procedures. The study outlines current trends and developments with respect to internet governance and places these into the broader political context of governmentality. The tendency to regard the internet as a single, coherent unit that can be understood in isolation does not reflect its infrastructure and the vested interests it serves. These comments should also be considered against the backdrop of a perceived increasing corporatisation of the internet - the relative closure of the promised openness of the internet and the decline of its libertarian potentialities under free market principles (Lovink, 2002, p.2). Yet, file exchange within peer to peer networks and the free and open source software movement demonstrate how the network itself is adaptive and somewhat resistant to the controls exerted upon it. Applied to the development of software in general, the collaborative gathering and analysis of information is referred to by Stalder and Hirsh (2002) as 'open source intelligence'. They point to the open source principles of peer review, the free sharing of products, and flexible levels of involvement and responsibility that are all derived from practice and the technical possibilities of 'network culture'. Free and easy information-sharing among peers, is exemplified in 'peer 2 peer' networks. By network culture, we mean to refer to the cultures and communities surrounding the internet and the values ascribed to these activities. Such examples demonstrate how technical expertise and socialised labour combine to offer both positive and negative potential, both releasing and limiting possibilities for future transformation (Terranova, 2004). The argument is that despite the severe limits on democratic structures, there remain opportunities to rethink politics within network cultures - and this is what is referred to in the article as 'non-representational democracy' to describe democracy decoupled from governmental power.

\section{Internet deployment implications}

The growth of the internet has been rapid, especially since 1988 when it began to roughly double every year. The internet provides a network of networks as illustrated in Figure 1. It has grown from a small research network connecting a rather limited number of nodes in the late 1960s to a network connecting a growing number of networks and systems together. The history of this is well documented from its origins as a research project for the US military involving three packet switched networks (ARPANET, Packet Radio Net and Packet Satellite Net) that were all developed under leadership funding of the Defense Advanced Research Projects Agency (DARPA). It subsequently absorbed Local Area Networks into its architecture; Ethernet, which was designed in 1973 by Bob Metcalfe at Xerox Palo Alto Research Center (PARC) is now the dominant wired LAN technology.

The protocol development of the internet started with the TCP/IP set of protocols (Transmission Control Protocol/Internet Protocol). TCP/IP protocols are layered one on top of the other and provide a wide range of capabilities (Fourazan, 2003). The most significant additions since the initial specification of TCP and IP include the Border Gateway Protocol (BGP), the Domain Name System (DNS) protocols and the application layer protocols (e.g., e-mail protocols such as POP3, IMAP and SMTP or World Wide Web protocols such as HTTP). Furthermore Voice over IP is being developed (e.g., Session Initiation Protocol) and more widely deployed. 
Figure 1 Internet - network of networks (see online version for colours)

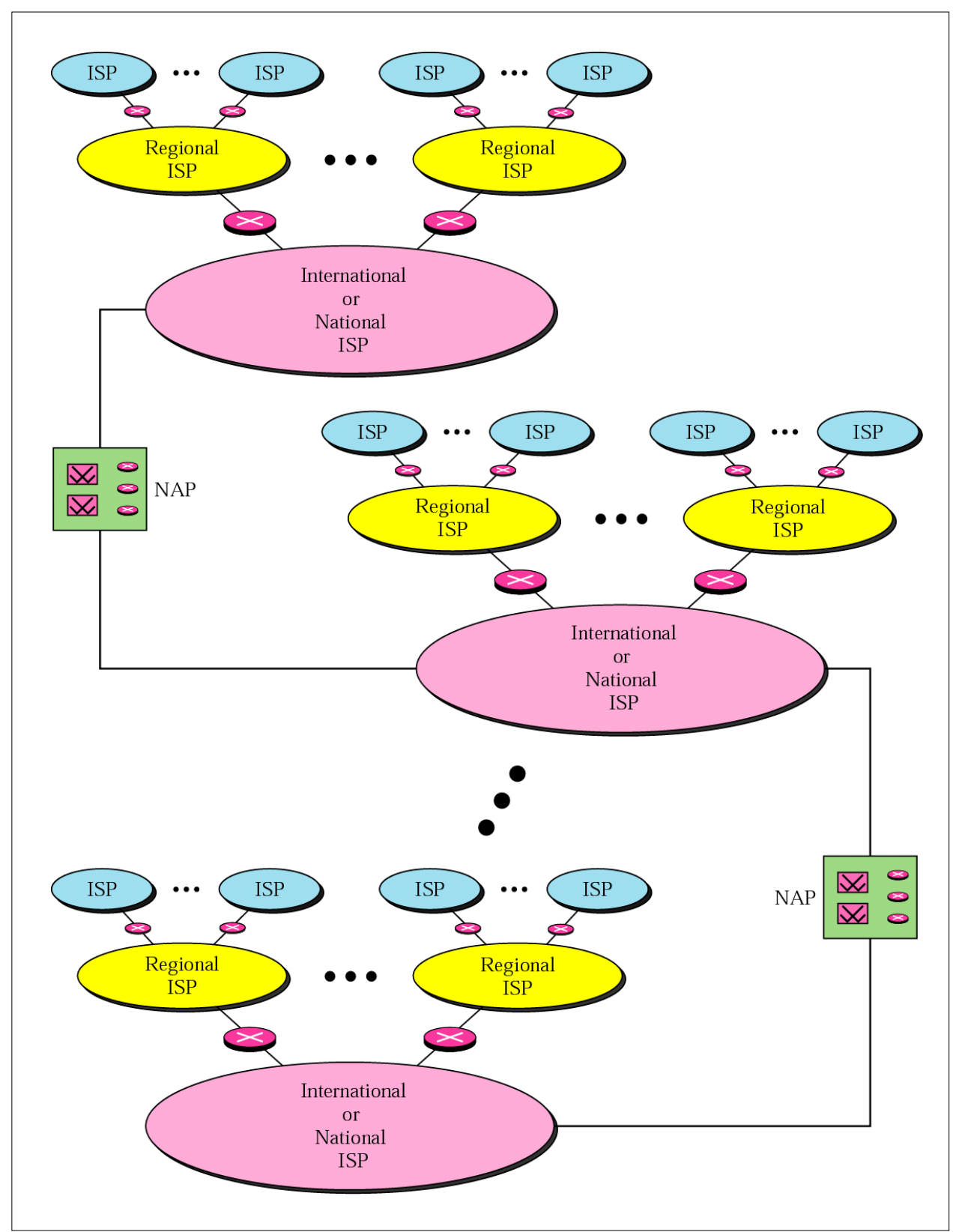

Issues of control and implementation of the above protocols goes some way to dispute any conception that the Internet is somehow inherently anarchic. On the contrary, control is expressed differently: no longer centralised or decentralised, but expressed in terms of distributed networks. The concept of the protocol as a set of recommendations and rules that outline specific technical standards is a neat analogy to describe the exercise of control within such systems and what stands for correct or proper behaviour (Galloway, 
2004). Protocols thus operate as a distributed management system coding packets of information, documents and communication. Computers in a network agree technical standards of action such that the protocols 'govern' usage at the level of code: 'protocol is a technique for achieving voluntary regulation within a contingent environment' as Galloway (2004, p.7) puts it. Voluntary regulation is a particularly successful mode of social control. This is not to say that control is necessarily bad of course and certainly protocols have no vested interest in themselves. The problem lies in the fact that standards are set and applied according to certain ruling interests - making it a political issue. The network is largely non-hierarchical in structure conforming to the way TCP/IP connects one machine to others, but is also subject to DNS information stored in decentralised databases but organised in hierarchical, inverted tree-structures (Galloway, 2004). At the top of the tree are a relatively small number of 'root' servers - mostly in the USA, Europe and Japan - that exert control over the lower branches. The technical detail reveals the operations of 'control societies' fraught with political contradictions rather like the 'free market' itself.

The content development of the internet has become a heterogeneous assembly of profit and non-profit, informational and political participants. The different political groups and movements represent both mainstream and oppositional as well as democratic, radical and reactionary ideas on a global and local level. However, after the excessive dot-com visions and growth of the late 1990s imploded (e.g., with respect to share prices of internet related companies), the conduct of the so-called 'war on terror' and global recession in the period since then, much of the visions and hype surrounding the internet have been reconsidered (although the current hype around Web 2.0 promises to counter this tendency once more). It can be argued that while the years leading to the dot-com crash were characterised by the commercialisation of the net, since then the years have been characterised by a widespread politicisation of the internet (Kahn and Kellner, 2005). On the one hand, oppositional, non-profit groups such as the Electronic Frontier Foundation (EFF) aim to protect the digital rights of internet users. On the other hand, governments plan to develop extensive information systems that will have implications with respect to information security (examples include projects such as the US governments Total Awareness Information project announced in 2002 that would potentially collect and collate information of individuals from a number of sources or the UK government's NHS database and online plans). These projects and the potential development of the internet and Information Technology generate heated and confrontational debates that pose a number of relevant questions. Hence globalisation in general and the development of the internet in particular are challenging critical theories and are having an impact on both democratic, radical as well as reactionary politics. The main issues and arguments of the current global political debate and economic globalisation are recognisable in the policy considerations and practices of governance and deployment of the internet (Christou, 2006).

The deployment and growth of internet services and online participation (Gibson, 2005) is facilitating the development from legacy network infrastructures towards new network infrastructures as summarised in Table 1. From a technical or network architectural point of view it performs the shift from circuit switching to packet switching network infrastructures. This shift is having a significant impact on issues such as governance (e.g., market or political versus self-regulatory) and market dominance (e.g., the provision of domain names are a crucial control point - potential dangers of abuse 
include exclusion or profiteering) (Collins, 2006). Both legacy and new network infrastructures require regulation if they are to serve the public's interest (e.g., enable competitive access to the local loop for the provision of broadband services or fair allocation of IP addresses).

Table 1 Legacy network infrastructure versus new network infrastructure

\begin{tabular}{|c|c|c|}
\hline Network category & Legacy network infrastructure & New network infrastructure \\
\hline Architecture & Circuit switching & Packet switching \\
\hline Routing & Closed call routing & ISP, dynamic routing \\
\hline Access & $\begin{array}{l}\text { Wired access to exchange } \\
\text { (i.e., wired local loop) and } \\
\text { backbone network }\end{array}$ & $\begin{array}{l}\text { Unbundled local loop and } \\
\text { decentralised backbone routing }\end{array}$ \\
\hline Addressing & Numbering assigned by operator & $\begin{array}{l}\text { Numbering assigned by ISP/internet } \\
\text { registry }\end{array}$ \\
\hline Standardisation & $\begin{array}{l}\text { National and international } \\
\text { regulations and standardisation } \\
\text { organisations }(e . g ., \text { ITU); } \\
\text { established procedures }\end{array}$ & $\begin{array}{l}\text { Centralised control and operation; not } \\
\text { formally embedded into established } \\
\text { procedures (e.g., ITU versus ICANN) }\end{array}$ \\
\hline Services and content & $\begin{array}{l}\text { Limited services (e.g., directory } \\
\text { enquiries, lottery announcements, } \\
\text { etc.) and interactivity }\end{array}$ & $\begin{array}{l}\text { Interactive and multimedia services } \\
\text { provided by internet service and } \\
\text { WWW content providers }\end{array}$ \\
\hline
\end{tabular}

A number of architectural and technical aspects are fundamental for the operation of the internet and the provisioning of internet services. The existence and possibility of an open market, transparency and competition heavily depends on internet governance (see Table 2). A prime example for the requirement of centralised and tightly-controlled internet governance (as opposed to market driven governance) lies in the areas of addressing and naming. As is the case for the legacy telephone network, it is required to have an ultimate authority with respect to address (and domain name) distribution to avoid (or resolve) potential addressing and naming disputes and ambiguities. On the other hand, it can be argued that competition may ultimately benefit customers in areas such as network access (e.g., with respect to performance and prices).

However government intervention may be required to facilitate the provisioning of affordable internet services and to nourish competition. For example, in the UK, Oftel (the UK's regulator for the telecommunications industry) has intervened on a number of occasions to create conditions for a competitive and user-centred market (Collins, 2006). Examples of interventions include Oftel's directives forcing British Telecom (BT) to introduce Flat Rate Internet Access Call Origination (FRIAC), to implement local loop unbundling or the release and pricing of wholesale datastream products. On a European level, the telecommunication industry has been transformed from predominantly uncompetitive state monopolies governed by a detailed (and rather restrictive) framework of regulations into a competitive market (Christou, 2006). The European Commission is largely responsible for the related legislation and the recent promotion of a liberal, multi-layer approach to the governance of the telecommunication market and industry (Christou, 2006; Sandholtz, 1998). These examples suggest that regulatory intervention is required to address the market position (and its impact upon competition) of major 
telecommunication players. This is making fair, efficient and transparent network and internet governance a prerequisite for the operation and development of the internet. However, what is missing from these approaches is a fundamental rethink of the nature of governance itself that is still based on the dualism of state or market organisational logic. Part of the issue here is that networks evidently display inherent difficulties for the very nature of government.

Table 2 Architectural and technical aspects

\begin{tabular}{ll}
\hline Category & Current state of the art \\
\hline Addressing & ICANN (monopoly) \\
Naming & $\begin{array}{l}\text { Domain names and domain name servicers ultimately } \\
\text { controlled by ICANN (monopoly) }\end{array}$ \\
& ISPs (competition) \\
Network access & $\begin{array}{l}\text { Limited competition between wired and wireless network } \\
\text { operators; some dominant suppliers for local access }(e . g ., \\
\text { broadband); competition further facilitated by regulation }\end{array}$ \\
& $\begin{array}{l}\text { Limited, but growing number of wireless providers } \\
\text { Network Access Points (NAPs) and } \\
\text { Internet Exchange Points (IXPs) }\end{array}$ \\
Different providers, however often dominated by a single \\
competitor (e.g., London Internet Exchange in the UK) \\
Competition, but strong presence of dominant players $(e . g .$, \\
Google for search engines)
\end{tabular}

\section{Network and internet governance implications}

Several assumptions prevail with respect to internet governance: that internet governance is distinct from governance of other media (e.g., television), that it is extending effectively through the whole internet community and that it is market driven. However a number a key players and driving forces behind the evolution of the internet put those assumptions in a different light and impact upon its current and future development. From a European perspective, the European Union Framework Directive excludes key elements such as internet addressing and naming from national bodies' responsibilities. This is opposed to other forms of international communications that are regulated by international and intra-governmental treaties (European Parliament and the Council of the European Union, 2002). Governance of the internet is divided between different institutions. The activities and authority of these are highly contested and remain uncertain. 
Figure 2 Authorities in the internet

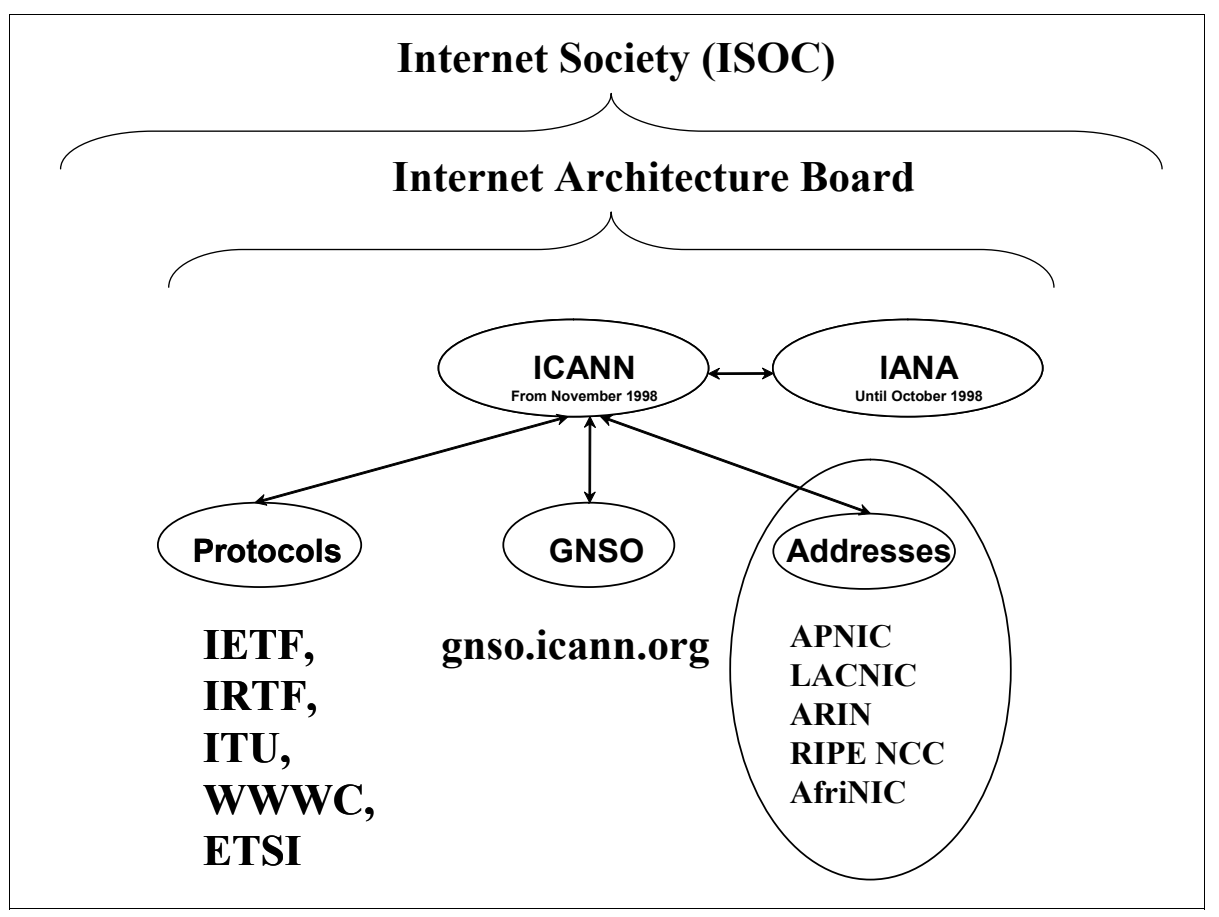

The Internet Society (ISOC) is an international, non-profit organisation formed in 1992 to provide support for the internet standards and development process. ISOC accomplishes this through maintaining and supporting other internet administrative bodies such as Internet Architecture Board (IAB) or the Internet Engineering Task Force (IETF). ISOC also promotes research and other scholarly activities relating to the Internet. The IAB is the technical advisor to the ISOC. The main purposes of the IAB are to oversee the continuing development of the TCP/IP Protocol Suite and to serve in a technical advisory capacity to research members of the internet community. IAB accomplishes this through its primary components, the Internet Engineering Task Force and the Internet Research Task Force (IRTF). Another responsibility is the editorial management of the IETF's Request for Comments (RFCs). IAB also facilitates external liaison between internet and other standards organisations and forums. The vast majority of internet related technological standards are developed and specified by the Internet Society (ISOC) and the units operating under ISOC: Internet Architecture Board (IAB), Internet Engineering Task Force (IETF), the Internet Research Task Force (IRTF), the Internet Research Steering Group (IRSG), Internet Engineering Steering Group (IESG), and the Request for Comments (RFCs) Editor. Whilst these organisations are responsible to ISOC, ISOC aims to ensure a large degree of independence in their technical work. IETF is a relevant and exemplary loosely self-organised, grass-roots technical group consisting of mainly of researchers, vendors and networking industry. It acts as an activity of ISOC and has no formal management (e.g., board of directors). There is no formal membership and generally, attendance at IETF meetings and subscription to IETF mailing lists is open to all volunteers. Participants are expected to contribute as individuals, rather than as representatives of companies or organisations. The IETF concerns itself with the 
engineering and architecture of the internet. It is the principal body that develops, tests and implements new internet technological standards, including protocols, that are published in the form of RFCs. The IETF relies on 'volunteers' (often representing the interests of an industry stakeholder) and uses 'rough consensus and running code' that results in a potentially slow process. Furthermore the number of contributors may either be too small to make progress or too large (i.e., making consensus difficult to reach). For protocols like Simple Mail Transfer Protocol (SMTP) which is used to transport e-mail over the internet, there is also considerable resistance to any change which is not fully backwards compatible. Given the number of contributors with opinions on standards issues is very large, consensus mechanisms on how to improve the standardisation process prove difficult to realise in practice.

The Internet Corporation for Assigned Names and Numbers (ICANN) is the non-profit corporation that was formed to assume responsibility for the IP address space allocation, protocol parameter assignment, domain name system management and root server system management functions (in conjunction with Generic Name Supporting Organisation, GNSO). This was formerly performed under a US Government contract by IANA and other entities. The IP Addresses are allocated by means of a central authority that franchises them to interested organisations. For Europe, ICANN has delegated authority to the Réseaux IP Européens (RIPE) Network Operations Centre (see Figure 3).

Figure 3 IP address distribution

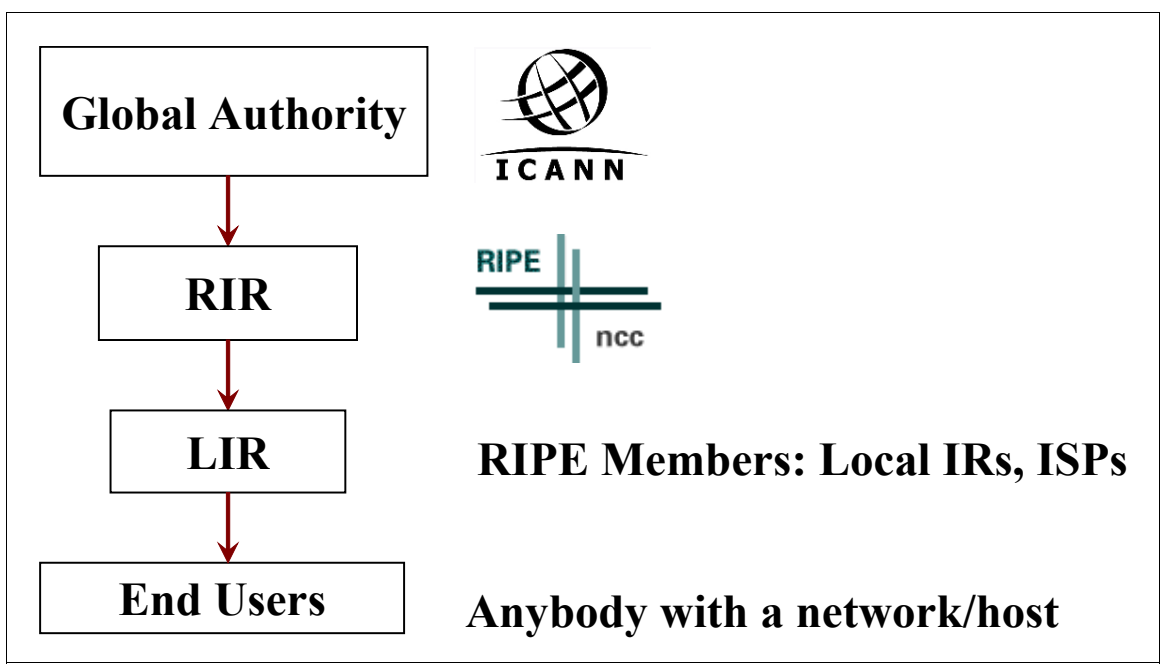

ICANN is a private organisation under Californian law set up by the US government during Bill Clinton's presidency in 1998 (in fact, the US government continued to act as an overseeing body). To reassure its critics the Department of Commerce (DoC) announced:

"We are looking for a globally and functionally representative organization,
operating on the basis of sound and transparent processes that protect against
capture by self-interested factions and that provides robust, professional
management. The new entity's process needs to be fair, open and
pro-competitive. And the new entity needs to have a mechanism for evolving
to reflect the changes in the constituency of internet stakeholders." (Burr, 1998) 
Since then, the National Telecommunications and Information Administration (NTIA), an agency of the USDoC acting as the president's principal adviser on telecommunications policies, has reiterated the aim of the US government to retain the 'historic role' and to continue 'being the steward' in conjunction with the DoC of the critical elements of the internet's underlying infrastructure, the domain name and the addressing system (Gallagher, 2005).

However, the independence and neutrality of ICANN remains in question (Mueller, 1999). Although the ICANN's board of directors is composed of members from different regions of the world to represent the heterogeneity of the internet community, the close relationship between ICANN and the US government remains. The US government have been heavily criticised for using its unique ICANN relationship to ICANN to its advantage. In one example, the administration of US President George Bush objected to the .xxx adult domain that eventually led ICANN to reverse an earlier decision and reject the domain suffix (Koppel, 2005). However, supporters of the controversial .xxx domain have been able to negotiate a new proposal with ICANN. Even though final approval of the contract is opposed by an interesting group of anti-pornography conservatives and pornographers with investments in existing adult domain names, there are chances that the proposal will eventually succeed in gaining the approval of the ICANN board (Mueller and Mathiason, 2007).

In September 2006 the US government extended an existing agreement between the Department of Commerce and ICANN for three years (although it could grant ICANN total autonomy after 18 months) (Kirk, 2006). In October 2006 ICANN further announced plans to develop new management operating principles, to improve upon the documentation of its board meetings and to redesign its website to improve the accessibility of its 12000 pages. All these measures aim to improve upon ICANN's transparency and to counter criticism. Other issues that must be addressed by internet governance include the proliferation of 'spam'. The importance of multilateral discussions and legislation has been widely recognised in the context of governments (e.g., the European Union) and telecommunications regulators. However, the fact remains that some analysts and researchers value ICANN as an independent body representing the interests of the internet community as a whole whilst others refer to it as a 'public-private partnership' (Collins, 2006; Froomkin, 2003; Christou, 2006). Nevertheless, the 'special relationship' of ICANN to the US government appears as a neat parallel to the way that the globalised economy increasingly relies on communications technology. It also serves to emphasise that governance is increasing influenced by the logic of markets and technology. Governments are thereby required to intervene, for better or worse.

\section{Current developments and future outlook}

\footnotetext{
"The role of government is not to create wealth; the role of our government is to create an environment in which the entrepreneur can flourish, in which minds can expand, in which technologies can reach new frontiers." (Gallagher, 2005)
}

The above quote forms the basis of George W. Bush's technology agenda and was proclaimed in November 2002. It appears to confirm that state control is increasingly exercised in partnership with other corporate interests outside of democratic structures. It 
also indicates how capital occupies a 'space of flows' (Castells, 1996) in contrast to the 'space of places' of historically created institutions and organisations of industrial society and the distinct role of government. Like the internet, the global economy is now characterised by the combination of 'an enduring architecture and a variable geometry' (Castells, 1996). What is required is both an understanding of the dynamic between the network model of organisation followed by corporations and the still powerful influence of the role of governments in influencing policy. It appears that effective governance must ultimately shift across and between these horizontal and vertical axis of influence.

The example of ICANN fits this description and reveals some of its contradictions. ICANN decides on new top-level domain names and delegates the implementation and management of existing and new domains in conjunction with the Governmental Advisory Committee (GAC). ICANN is intent on keeping the existing model and aims to evolve rather than being replaced by a new model of communal state-led internet governance. On the other hand, the modelling and implementation of new structures for internet governance is the clear intention of a large proportion of the international community (Wray, 2005). The position regarded as a control-oriented approach proposed and supported by a number of states (e.g., China, Pakistan) aims to create a new governing council based in the United Nations (UN) that would oversee ICANN and to which it would be accountable. Another approach envisages a 'lightweight' governance structure (initially recommended by the EU) based on a cooperation model encompassing governments, industry and other relevant organisations dealing and overseeing ICANN, and a forum to provide a recommendations and proposals for internet practice and operation. At the same time, a discussion surrounding the possible control (i.e., censorship) surrounds this, with some players seemingly more concerned with the control of content than others (e.g., the official EU position is that the cooperation model is not about content and it advocates free speech on the internet).

In January 2002 the United Nations General Assembly issued a proposal on Information and Communication Technology (ICT) issues leading towards the World Summit on the Information Society (WSIS) series of United Nations sponsored conferences (Kleinwaechter, 2004). The task of organising and running the WSIS leading to the global summit of Tunis in November 2005 was delegated to the International Telecommunications Union (ITU). The ITU can be seen as a potential key player in counterbalancing the hegemonic power of the US government and ICANN. However the internet community seems unconvinced of ITU's ability to play a constructive role in the development and governance of the internet, given the failure of 'global' standards such as the OSI model and its perceived history of bureaucracy and sluggishness. At Tunis, discussions over internet governance and the role of ICANN dominated the conference, leading to the 'decision' to leave overall control with ICANN. Additionally it was decided to establish the purely consultative Internet Governance Forum (IGF). Supporters of the outcome argue that the concern over US dominance over the internet (e.g., with respect to freedom of information) are insubstantial and that the USA will guarantee the best possible development of the internet. However the given status quo remains controversial to say the least and contested given its strategic economic, cultural and technological importance (Christou, 2006; Collins, 2006). It can be argued that further refinement of internet governance must be linked to wider regulatory changes of a predominantly globalised economy and international governance. 
A number of critics of the United Nations-led IGF are concerned by the lack of any decision-making abilities with respect to the core aspects and ideological issues surrounding internet governance. A recent IGF meeting in Athens was overshadowed by discussions of the role of ICANN and the clash of opinions. Whilst the European Union endorsed an announcement by the US Department of Commerce to consider ending its control of ICANN, the International Telecommunication Union (ITU) regarded the same issue as making 'little or no change' (Blau, 2006). The lack of any real decision-making abilities makes it difficult to evaluate the results or recommendations from the IGF at this stage.

It has been demonstrated that state as well as market forces influence the governance of network access and content. Additionally network forms of governance are having a major impact upon the control and operation of the internet. It becomes clear that the internet is subject to diversification with respect to governance and not surprisingly more prominent network governance than other communication channels (e.g., based on legacy network infrastructures). This suggests that network governance and self regulation have the potential to contribute towards efficient and constructive governance. However, this discredits the notions of 'market knows best' and that the internet is distinct from issues surrounding legacy media. It can further be stressed that given the variety and complexity of state-industry relation that self regulation 'is almost a misnomer... [which] rarely exists without some relationship between industry and the state' (Price and Verhulst, 2005). Cases such as the .eu Top Level Domain (TLD) provide evidence of international private-public governance in the internet community and this reflects the development towards post-regulatory state governance (Christou, 2006).

Institutional cooperation has been instrumental to the development of the internet. The IETF and ICANN provide a revealing contrast of different organisational and internet governance cultures. It can be argued that ICANN has partly 'failed' because it represents a move away from traditional internet self-governance and that it is ideologically compromised given its close links to the government of a nation state (i.e., the USA). It can also be argued that ICANN's effectiveness has been impeded by a lack of autonomy and by its dependence upon the US government to legitimate its rule. The resulting lack of an established culture has undermined the achievement of an effective and successful modus operandi (Bowrey, 2005). It can further be argued that the main internet governance body ICANN lacks transparency and clear formalised procedures. To counter this it is required to formulate clear guidelines or laws that formulate the scope of government interests and ICANN's role. In contrast, the IETF has always had a clear mission statement and 'voluntary' participation which has enabled it to evolve and renew itself. Given the predominantly technical nature of its tasks, it facilitates an relatively open, fair and transparent modus operandi.

The internet is best understood as a network of networks with a multitude of loosely interconnected and layered entities as opposed to one closed medium or infrastructure. It should not (and as this research suggests cannot) have a single, unified governance organisation. It is a dynamic and evolving organism with constantly changing operational and governance requirements. Thus the necessity of different forms of governance must be acknowledged. 


\section{Towards a non-representational democracy}

"... while networks in many ways are regulated indirectly by the
sovereign interests of the state, they are also not reducible to institutional
apparatuses of the state. And this is what makes possible the creation of new
institutional forms as expressions of non-representational democracy."
(Rossiter, 2006, p.39)

The problems associated with governance outlined in this article reflect broader political structures and the ways in which the world market is constituted differently and the extent to which governmentality itself has evolved and been absorbed by other institutional bodies. The globalisation of capitalist production has given rise to a new form of sovereignty that is no longer based on the model of the nation-state and its representational structures of government (Hardt and Negri, 2000). The claim is that the 'new paradigm is both system and hierarchy' and demonstrates the structural logic of 'governance without government' (Hardt and Negri, 2000, pp.13-14). In this way, the direct role of government and the dominant thinking associated with it can be seen to be entirely problematic. In Organized Networks (2006), Rossiter asserts that there is an urgent need for new institutional forms that reflect 'relational' processes that challenge existing systems of governance and representational structures. The argument arises from the apparent inadequacy of modern institutions to respond to the impact of socio-technical networks. Emergent forms are radically dissimilar to the ways in which social relations are organised under what Rossiter refers to as the 'moribund technics' of modern institutions. These older forms, characterised as 'networked organisations', are hierarchical and centralising despite the rhetoric of apparent democracy and devolution. In contrast, emergent 'organised networks' are horizontal, collaborative and distributed in character offering a distinct social dynamic and transformational potential. The difference characterisations are illustrated in how institutions have responded to the central importance of intellectual property rights: on the one hand, networked organisations using this as a regulatory mechanism to enforce or extend existing power structures, and on the other, organised networks advocating open source culture (Rossiter, 2006) - or more precisely advocating 'peer property' as a consequence of production associated with free and open source principles.

The argument is that new social processes arise directly from network cultures that challenge some of the existing paradigms of representational democracy. Emergent democratic activity is somewhat demonstrated in the socio-technical dynamics of mailing lists, blogs, wikis, content management systems, and so on. For instance, peer to peer networks allow for a distinct form of production - 'peer production' - relatively outside of the market and state influence (Benkler, 2006). Similarly, 'peer governance' is non-hierarchical and represents an alternative to forms of governance, one based on civil society rather than on representational democracy. It is the institutional nature of this, as a description of the organisation of social relations, that makes it a thoroughly political issue (Rossiter, 2006). Organised networks represent relative institutional autonomy but not in isolation - they also need to operate tactically, engaging horizontal and vertical modes of interaction in recognition of their socio-technical architectures (Rossiter, 2006, p.36). Only in this way is politics invoked.

Networks are clearly not limitless or without borders, but (like the free market) the situation is far more complex. Far from arguing against the role of institutions, the limits of democracy and governance can be seen to be a means to rethink politics 
within network cultures and offer opportunities to develop strategies and techniques of better organisation without government intervention. This is what we refer to as 'non-representational democracy' to describe democratic processes decoupled from govermentality constrained by market and state interests. The suggestion is that emerging forms from within network culture challenge the foundations of internet governance and offer alternative possibilities.

\section{References}

Barabási, A-L. (2002) Linked: The New Science of Networks, Cambridge, MA: Perseus.

Benkler, Y. (2006) The Wealth of Networks: How Social Production Transforms Markets and Freedom, Yale University Press.

Blau, J. (2006) 'Internet forum participants clash', Computerworld - The Voice of IT Management, 3 November, http://www.computerworld.com.au/index.php?id=2072639607 (retrieved 11 November 2006).

Bowrey, K. (2005) Law \& Internet Cultures, Cambridge University Press, 30 May.

Burr, B. (1998) Department of Commerce Press Conference, Washington, 5 June.

Castells, M. (1996) The Rise of the Network Society, Oxford: Blackwell.

Christou, G. (2006) 'The internet and public-private governance in the European Union', Journal of Public Policy, Vol. 26, No. 1, pp.43-61.

Collins, R. (2006) 'Internet governance in the UK', Media, Culture \& Society, Vol. 28, No. 3, pp.337-358.

European Parliament and the Council of the European Union (2002) Directive 2002/21/EC of 7 March 2002 on a Common Regulatory Framework for Electronic Communications Network and Services, OJL 108/33, 24 April.

Forouzan, B. (2003) TCP/IP Protocol Suite, International edition, McGraw-Hill.

Froomkin, M. (2003) 'ICANN 2.0: meet the new boss', Loyola Law Review of Los Angeles, Vol. 36, No. 3.

Gallagher, M. (2005) 'Internet's domain name and addressing system: U.S. principles on the internet's domain name and addressing system', Wireless Communications Association International: 2005 International Conference, 30 June, http://www.ntia.doc.gov/ntiahome/ speeches/speechesindex2005.htm (accessed 11 November 2006).

Galloway, A. (2004) Protocol: How Control Exists After Decentralization, Cambridge, MA: MIT Press.

Gibson, R. (2005) 'Online participation in the UK: testing a 'contextualized' model of internet effects', Political Studies Association, BJPIR, Vol. 7, pp.561-583.

Hardt, M. and Negri, A. (2000) Empire, Cambridge, MA: Harvard University Press.

Kahn, R. and Kellner, D. (2005) 'Oppositional politics and the internet: a critical/reconstructive approach', Cultural Politics, Vol. 1, No. 1, pp.75-100.

Keohane, R. and Nye, J. (1998) 'Power and interdependence in the information age', Foreign Affairs, Vol. 77, No. 5, pp.81-94.

Kirk, J. (2006) 'ICANN to undergo transparency review: DNS administrator to undergo review by One World Trust', Computerworld - The Voice of IT Management, 20 December, http://www.computerworld.com.au/index.php/id;1467618322;fp;;fpid;;pf;1 (retrieved 5 January 2007).

Kleinwaechter, W. (2004) 'Beyond ICANN vs ITU?', Gazette: The International Journal for Communication Studies, Vol. 66, Nos. 3-4, pp.233-251.

Koppel or Koppell?

Koppell, J. (2005) 'Pathologies of accountability: ICANN and the challenge of "multiple accountabilities disorder", Public Administration Review, Vol. 65, No. 1, pp.94-108. 
Lovink, G. (2002) Dark Fiber: Tracking Critical Internet Culture, Cambridge, MA: MIT Press.

Mueller, M. (1999) 'ICANN and internet governance - sorting through the debris of 'self-regulation', Info, Vol. 1.

Mueller, M. and Mathiason, J. (2007) 'Triple X, internet content regulation and the ICANN regime', Internet Governance Project, Paper IGP07-001, http://www.internetgovernance.org/ pdf/new-xxx-contract.pdf (retrieved 21 January 2007).

Price, M. and Verhulst, S. (2005) Self Regulation and the Internet, Kluwer Law International, The Hague.

Rossiter, N. (2006) Organized Networks: Media Theory, Creative Labour, New Institutions, Rotterdam: NAi/Institute of Network Cultures.

Sandholtz, W. (1998) 'The emergence of a supranational telecommunications regime', European Integration and Supranational Governence, Oxford University Press, pp.134-163.

Slaughter, A.M. (2001) 'The accountability of government networks', Indiana Journal of Global Legal Studies, Vol. 8, No. 2, pp.347-367.

Stalder, F. and Hirsh, J. (2002) 'Open source intelligence', First Monday, June, Vol. 7, No. 6, http://firstmonday.org/issues/issue7_6/stalder/index.html.

Terranova, T. (2004) Network Culture: Politics for the Information Age, London: Pluto Press.

Wray, R. (2005) 'EU says internet could fall apart', The Guardian, 12 October. 